\title{
Developing teamwork and other professional skills while teaching reinforced concrete design
}

\author{
Anne GARDNER \\ Faculty of Engineering \\ University of Technology, \\ Sydney \\ Sydney, Australia \\ Anne.Gardner@uts.edu.au \\ Anne Gardner, received her \\ Master of Engineering Studies in \\ structural engineering from the \\ University of Sydney in 1996. \\ Her research interests in the area \\ of engineering education include \\ self and peer assessment, and the \\ learning and teaching of \\ mechanics and structures.
}

\author{
Keith WILLEY \\ Faculty of Engineering \\ University of Technology, \\ Sydney \\ Sydney, Australia \\ Keith.Willey@uts.edu.au \\ Keith Willey, received his $\mathrm{PhD}$ \\ in 2002 from the University of \\ Technology, Sydney. He \\ accepted an academic position \\ after a 20 year industry career. \\ His professional interests include \\ satellite communications, \\ biomedical applications and \\ using self and peer assessment to \\ build professional skills and \\ productive teams.
}

\section{Summary}

Professionals, in addition to being technically competent, need a range of generic skills. These include teamwork, communication, being able to think both critically and independently, being able to critically appraise one's work and the work of others and an appreciation of the need and value of reflection in both their personal and professional life [1,2]. However, there is a reported competency gap between the skills required by employers and those developed by students during their undergraduate courses [3,4]. At the University of Technology, Sydney, we are using self and peer assessment in our Engineering program to develop professional competencies in undergraduate engineering students. Its co-ordinated use is providing opportunities for students to practise, develop and assess their professional skills and develop their judgement [5] within subjects where traditional discipline content is taught.

Keywords: self and peer assessment, graduate attributes, teamwork, online tools, SPARK, reinforced concrete education.

\section{Introduction}

Professionals, in addition to being technically competent, require the skills of collaboration, communication and the ability to work in teams $[1,2,6,7]$. However, there is a reported competency gap between the skills required by employers and those developed by students during their undergraduate courses [3, 4]. Scott and Yates [2] note that successful engineering graduates rated their ability to contribute positively to team-based projects as the most important of 49 possible reasons for their success. Technical expertise, while acknowledged as necessary, and receiving the greatest amount of teaching time during their degree, was rated a comparatively low 29th. In response to this, universities both in Australia and internationally [8] have introduced attributes which their students should develop during their degree.

Generic attributes are typically required in the practice of all professions. For example attributes shared by most disciplines include teamwork skills, being able to think both critically and independently, being able to appraise one's work and the work of others, and an appreciation of the need and value of reflection in their personal, and professional life.

Research into what engineers actually 'do' at work reported that much of their time is spent coordinating the work of other people [9]. Trevelyan proposes that instruction and practice in the development of these professional skills has to be "combined with technical expertise for effective 
co-ordination." [10]

Universities often use team-based projects to develop these professional skills in their undergraduate students. While such projects increase the opportunities for team interaction they do not necessarily facilitate the development of teamwork skills $[10,11]$ : teamwork doesn't automatically happen. Students need to understand team dynamics, how to resolve conflict and be able to both give and receive feedback.

While development of these skills is facilitated by instruction, it is insufficient on its own [12,13]. University courses need to develop learning-oriented assessments that not only encourage these skills to be developed but promote future development and learning after graduation [14]. If we are to successfully achieve teamwork and professional skill development as outcomes, we need a method of assessment, auditing and feedback that promotes these outcomes.

Within the engineering program at the University of Technology, Sydney (UTS), we are coordinating the use of self and peer assessment to provide students with opportunities to practise, develop and assess their professional skills and develop their judgement [5], including within subjects like Structural Design 1 where traditional reinforced concrete content is taught.

The use of self and peer assessment has been widely reported in the literature $[14,15,16,17]$. While its use for summative assessment has proved effective in discouraging group free riders and promoting collaboration, our research has found that using it to produce formative learning-oriented feedback to complete the learning cycle significantly improved students' learning outcomes $[18,19]$. In addition to promoting academic honesty, its use encouraged ongoing skill development and improvement in the quality of subsequent contributions.

Specific attributes are also required by professional organisations to obtain degree program accreditation or for their members to obtain professional accreditation. For example Engineers Australia Accreditation Policy [20] lists attributes divided into three Units of Competency:

Unit 1: Engineering Knowledge

Unit 2: Engineering Ability

Unit 3: Professional Skills

Self and peer assessment can not only be used to promote students to learn and develop outcomes within these categories but assessment metrics can be used to monitor and track this development throughout a subject or an entire degree program.

Incorporating self and peer assessment, especially in large classes, is impractical without the assistance of online tools. However the success of such tools in improving students' learning and attribute development depends critically on how academics implement them within their subjects [21]. In this paper we discuss our use of an online tool called SPARK (Self and peer Assessment Resource Kit [22] to integrate the development of graduate attributes while teaching reinforced concrete design.

\section{Using SPARK for self $\&$ peer assessment}

SPARK is an online tool that facilitates the collection of confidential self and peer evaluations. Feedback and assessment can be either aggregate (assessment of the students' overall contribution to the project) or category based where the assessment and feedback is reported over a number of different categories or attributes. SPARK automatically generates both a performance and a feedback assessment factor. The Self and Peer Assessment or SPA factor, as shown in Equation (1), is a weighting factor that can be used to determine an individual's contribution to a team project by the relationship shown in Equation (2).

$$
\begin{array}{r}
\text { SPA Factor }=\sqrt{\frac{\text { Total ratings for individual team member }}{\text { Average of total ratings for all team members }}} \\
\text { Individual mark }=\text { team mark * Individual's SPA }
\end{array}
$$

The second factor calculated is the Self Assessment to Peer Assessment or SAPA factor (Equation 
3). It is the ratio of a participant's own rating of themselves compared to the average rating of their contribution by their peers. Used appropriately this has strong feedback value for a participant's ongoing development. For example, a SAPA factor greater than 1 means that a student has rated their own performance higher than they were rated by their peers. Conversely, a SAPA factor less than 1 means that a student has rated their own performance lower than they were rated by their peers.

SAPA Factor $=\sqrt{\frac{\text { Self ratings for individual team member }}{\text { Average of ratings for individual by peer team members }}}$

These metrics are used to provide feedback enabling participants to identify weaknesses in and hence improve their performance in individual attributes for subsequent assessment tasks.

\begin{tabular}{|c|c|}
\hline SELECT SUBJECT: & GROUP NAME: \\
\hline 48359 Structural Design 1 & The-Knuckle Heads \\
\hline SELECT TASK: & SELECT PEERS to VIEW: \\
\hline Task 1 - Design Project Part 1 & Ruth \\
\hline ENGINEERING KNOWLEDGE & SPA: 0.91 \\
\hline $\begin{array}{l}\text { 1. Demonstrated understanding of how to use stength interaction } \\
\text { diagrams }\end{array}$ & \begin{tabular}{|l|l|l|l|l|} 
WB & $B g$ & $g$ & $g$ & Wo \\
\end{tabular} \\
\hline $\begin{array}{l}\text { 2. Understands how to calculate } N^{\star}, M^{*} x \& M^{*} y \text { for column for } 2 \text { way } \\
\text { slab }\end{array}$ & 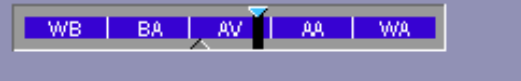 \\
\hline 3. Understands how to calculate $N^{\star}, M^{*} x \& M^{*} y$ for column for flat slab & 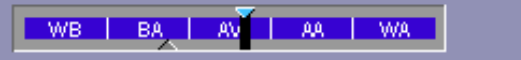 \\
\hline \multirow{3}{*}{$\begin{array}{l}\text { ENGINEERING ABILITY } \\
\text { 1. Competent in designing appropriate steel areas for columns } \\
\text { 2. Created drawings of specified standard for the elements designed }\end{array}$} & SPA: 1.05 \\
\hline & 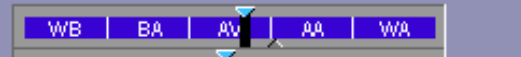 \\
\hline & \begin{tabular}{|l|l|l|l|l|} 
WB & $\mathrm{Bg}$ & $\mathrm{v}$ & $\mathrm{ga}$ & $\mathrm{wa}$ \\
\end{tabular} \\
\hline \multirow{5}{*}{$\begin{array}{l}\text { PROFESSIONAL SKILLS } \\
\text { 1. Providing constructive feedback to team members } \\
\text { 2. Resolving / Managing team conflict }\end{array}$} & SAPA: 0.99 \\
\hline & 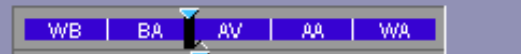 \\
\hline & \begin{tabular}{|l|l|l|l|l|}
$\mathrm{WB}$ & $\mathrm{Bg}$ & $\mathrm{av}$ & $\mathrm{ga}$ & $\mathrm{wg}$ \\
\end{tabular} \\
\hline & \begin{tabular}{|l|l|l|l|l|} 
WB & $\mathrm{Bg}$ & $\mathrm{d} / \mathrm{g}$ & $\mathrm{go}$ & $\mathrm{wa}$ \\
\end{tabular} \\
\hline & $\begin{array}{l}\text { SPA factor: } 0.96 \\
\text { SAPA factor: } 1.03\end{array}$ \\
\hline
\end{tabular}

Figure 1: Feedback and performance factors for student named Ruth (the criteria shown are a subset of the criteria used in the subject Structural Design1).

Each self and peer assessment exercise involves students rating themselves and their team peers against a number of criteria determined by the academic. The academic categorises each criteria as being either Engineering Knowledge, Engineering Ability or Professional Skills. As an example a subset of the criteria used in Structural Design 1 is shown in Figure 1. Categorising the criteria in this way allows students to receive individual feedback on their performance in each category as well as their overall performance ratings as previously described.

For example let us assume that Figure 1 reports the feedback and performance factors for a student named Ruth. Referring to the figure it can be seen that the aggregate performance or SPA factor (0.96) indicates that Ruth is performing well, contributing only slightly lower than the average performance of her team peers. The formative feedback or SAPA factor of 1.03 indicates that Ruth's opinion of her performance is approximately the same as the average opinion of her performance by her team peers. There is no indication as to what areas, if any, within which Ruth may need to improve her performance. However, further insight is gained by looking at the 
category factors for each attribute. These report that:

Engineering Knowledge: Ruth's contribution to the team's required Engineering Knowledge is below the average of her team peers $(\mathrm{SPA}=0.91)$. Perhaps more importantly the SAPA factor of 1.21 indicates that Ruth is unaware that her peers feel she is underperforming in this area. Ruth feels she has made a much greater contribution.

Engineering Ability: Ruth's Engineering Ability contribution to the team is above the average of her team peers $(\mathrm{SPA}=1.05)$. Furthermore the SAPA factor of 0.9 indicates that Ruth underrates the significance of her contribution and may not be aware how highly her team peers regard her contribution in this catagory.

Professional skills: Ruth's contribution to the team using her professional skills is below the average of her team peers $(\mathrm{SPA}=0.92)$. The SAPA factor of 0.99 (very close to 1$)$ indicates that Ruth is aware that her contribution was below average. Ruth needs to seek feedback from her team peers and reflect on the reasons for her poor contribution, addressing any identified issues to improve her professional skills and subsequent performance.

In summary, analysis of the category factors indicates that Ruth's strength is her Engineering Ability, That is, her ability to apply her engineering knowledge to solving a problem while considering any technical, social, environmental and economic impacts and constraints. Her weaker areas of contribution to this team are her Engineering Knowledge and Professional Skills. Furthermore prior to receiving this feedback Ruth may have been unaware that she was underperforming in her contribution to the teams required Engineering Knowledge and did not appreciate how highly the team rated her Engineering Ability.

This feedback allows Ruth to build on her strengths and address her weaknesses. It also allows academics to monitor these strengths and weaknesses to provide specific feedback and coaching to assist Ruth in her attribute development.

The fact that SPARK is a criteria-based tool allows academics the flexibility to choose or create specifically targeted criteria to allow any task to be assessed, including the development of generic AND discipline-specific attributes. In addition, using common categories (like the three described above) throughout a degree program, to which academics link their chosen criteria, allows the results to be recorded, providing a means for both academics and students to monitor and track a student's attribute development as they progress through their degree.

While we acknowledge that these assessments may not always accurately reflect the actual level of a student's attribute development, as they are the result of subjective assessments by group members, it does provide a useful guide and indeed mirrors the professional situation where an individual's contribution and performance is judged by their peers. In addition, if multiple peers are used (eg teams of size 4 to 8 ) in the evaluation process any bias from a single member of the evaluation group tends to be averaged out.

Our aim has been to use self and peer assessment to facilitate specific, targeted feedback from both academics and team peers and generate measured improvement within a single semester while simultaneously developing skills that will promote a positive attitude to lifelong learning. To achieve this we have found it necessary to use self and peer assessment multiple times during a semester [23]. The use of an online tool makes this possible, even in large classes, without an unmanageable administrative burden.

\section{Self \& peer assessment in Structural Design 1}

In the subject Structural Design 1 self and peer assessment is used to assess work, assign marks and provide feedback on a combination of both discipline specific and generic professional attributes with which students must engage in completing a major group project.

Structural Design 1 is a subject taken by all civil, civil and environmental, and construction engineering students at UTS. The subject's primary aims are to develop students' understanding of the behaviour of reinforced concrete structural elements such as beams, slabs and columns, and to develop competence in using and interpreting the Australian Standard for Structural Design Actions (AS/NZ 1170) [24] and for Concrete Structures (AS3600) [25]. The subject introduces students to the fundamentals of the structural design process and the philosophy of limit state design. Students 
are required to apply their knowledge of solid mechanics, structural analysis and construction materials to the design of sound, safe, economical and durable reinforced concrete structural components.

The assessment tasks were re-designed as a design project for the Spring 2007 semester to accommodate group work and the inclusion of the self and peer assessment process. In their design project, students work in teams of 3 or 4 to design beam, slab and column elements for one storey of a low-rise reinforced concrete building. The design project consists of three staged assessment tasks where students submit their design calculations, decisions and drawings: 1. Loading and Beam Design, 2. Floor System Design, and 3. Column Design. A combination of lectures and tutorials are used to examine the design and analysis required to address each part of this project. Students also attend a laboratory session where three concrete beams are tested to destruction to illustrate three different failure modes.

The project was designed to be too much work for one or two students to complete alone, so that students were forced to work collaboratively to complete the assessment tasks. The project also required students to make design recommendations ie to use their engineering judgement. Students were asked to complete two designs for the floor system, the first as a two-way slab and the second as a flat slab; each group then had to recommend one of these floor systems for their project, and justify their recommendation. Decisions made about one element of a design inevitably affect other elements in the system. This was reinforced when the students were required to design the columns for their building using both floor systems. Students could see how the design requirements for the columns varied depending on the floor system used. Having to explain and justify their design is excellent preparation for students who will have to explain their work to a supervisor or client in the workplace.

To promote the development of both discipline-specific and generic professional skills, as well as academic honesty, a process of self and peer assessment is used in this subject. The results of these assessments are used to provide constructive feedback to students as well as to determine individual assignment marks by appropriate adjustment of group marks. In the implementation reported here the original version of SPARK was used. This version only produces aggregate SPA and SAPA factors.

Students were given three specific opportunities through the semester to assess themselves and their peers and receive feedback using the self and peer assessment process. SPA and SAPA factors were shared with all members of a group to encourage honest assessments. In this subject one staff member was responsible for lecturing, tutoring and facilitating the feedback sessions. This staff member had some experience in using the self and peer assessment process and facilitating the feedback sessions in other subjects but had not previously been solely responsible for their implementation.

\section{Results and Discussion}

An online post subject survey was used to obtain student feedback. Most survey questions were written in 5-point Likert format. The results are summarised in Table 1. Where there are two percentages given the first reports the combined percentage of the two positive response options with the percentage of neutral responses is shown in brackets (only for the Likert format questions).

Since this was the first time that self and peer assessment processes had been used in Structural Design 1 it is difficult to make any definitive conclusions. However, a number of results provide some interesting insights.

Most respondents (84\%) had prior experience with using self and peer assessment including its ability to expose free riders, before they commenced Structural Design 1 . We suggest this contributed to the fact that $85 \%$ of respondents reported that their team did not have any poor members and $90 \%$ reporting that their team functioned well throughout the semester.

Perhaps the most encouraging result was the fact that a significant number of respondents reported that their group and their tutor provided them with useful formative feedback $(52 \% \& 54 \%$ respectively) and that the project enabled them to develop skills in working as part of a team (56\%). Respondents reported that the formative feedback they received from their group members and tutors helped them not only to improve their performance in the subject (37\%) but also expect it to 
help them improve their performance in future subjects (34\%).

Table 1: Post self and peer assessment survey results for Structural Design 1

\begin{tabular}{|l|l|}
\hline Cohort & 63 \\
\hline Respondents & 41 \\
\hline Respondents who had previous experience using self and peer assessment & $84 \%$ \\
\hline My team functioned well throughout the semester & $90 \%$ \\
\hline My team did not have any poor members & $85 \%$ \\
\hline $\begin{array}{l}\text { Multiple uses of self and peer assessment and the associated feedback sessions improved my } \\
\text { ability to both assess my work and the work of others. }\end{array}$ & $34 \%(29 \%)$ \\
\hline $\begin{array}{l}\text { Multiple uses of self and peer assessment and the associated feedback sessions improved my } \\
\text { ability to both give and receive feedback }\end{array}$ & $39 \%(34 \%)$ \\
\hline $\begin{array}{l}\text { Multiple uses of self and peer assessment and the associated feedback sessions enabled me to } \\
\text { respond to the feedback to improve my team contribution during the semester }\end{array}$ & $39 \%(31 \%)$ \\
\hline $\begin{array}{l}\text { Multiple uses of self and peer assessment and the associated feedback sessions enabled me to } \\
\text { respond to the feedback to improve my interpersonal and teamwork skills during the semester }\end{array}$ & $39 \%(36 \%)$ \\
\hline My group provided me with useful formative feedback throughout the semester & $52 \%(29 \%)$ \\
\hline My tutor provided useful formative feedback in the feedback sessions & $54 \%(17 \%)$ \\
\hline $\begin{array}{l}\text { The formative feedback I received from my group helped me to improve my performance in } \\
\text { the subject. }\end{array}$ & $37 \%(29 \%)$ \\
\hline $\begin{array}{l}\text { The formative feedback I received from my group will help me to improve my performance in } \\
\text { future subjects. }\end{array}$ & $34 \%(39 \%)$ \\
\hline Using self and peer assessment facilitated by SPARK improved my group work experience & $32 \%(24 \%)$ \\
\hline Overall the project has enabled me to develop skills necessary for working as part of a team. & $56 \%(22 \%)$ \\
\hline
\end{tabular}

These results indicate that approximately one third of respondents were receiving and acting on constructive feedback from their peers. Furthermore, respondents reported an improvement in their professional skills, including their ability to give and receive feedback (39\%) and their assessment ability (34\%), which requires students to develop their judgement. This may not have occurred without the use of self and peer assessment and its integrated feedback processes. While these results demonstrate the potential benefit of applying these processes, the results were less positive than implementations in other engineering subjects at UTS [23].

We suggest that this may be partly due to the fact that these other subjects applied self and peer assessment processes to existing group work projects while Structural Design 1 was specifically redesigned to include group work activities. This involved not only changing the assessment regime but both extended and raised the level of activity required of students to achieve the learning outcomes.

It is common for students to approach a subject with a plan of their activity based on information received from students who have previously completed that subject. The subject changes provided a mismatch with students' expectations and some struggled with applying self and peer assessment processes to a subject that had previously been focused on providing engineering knowledge and not extensively testing its application. This semester (Autumn 2008) the coordinating academic has specifically devoted lecture time to provide instruction on why self and peer assessment is used in this subject, including exposure to some of the research. We will again survey students at the end of this semester to determine whether this has increased students' engagement with, and benefit from the subject's learning outcomes, both generic and reinforced concrete specific.

In previous research we have found that facilitation by an experienced academic significantly increased the benefit students receive from the feedback produced from self and peer assessment processes [23]. While the majority of students (84\%) had used self and peer assessment before commencing Structural Design 1 and hence needed less micro-management during the feedback 
sessions, the tutorial class had twice as many students as some other subjects using similar self and peer assessment processes at UTS. This meant that there was only time for the co-ordinating academic to facilitate feedback with those groups whose feedback factors indicated that they were having some difficulty. While it is our intention to progress students from being novices to be more expert as they progress through their degree, and hence require less support, in future semesters we intend to provide students with more resources to assist them to independently gain more benefit from using self and peer assessment. The search for better methods to support students is the focus of ongoing research. This includes the increased feedback available with the newer version of SPARK which produces both aggregate and category SPA and SAPA factors as previously described in this paper.

\section{Conclusion}

In this paper we have presented a method demonstrating how the thoughtful implementation of self and peer assessment processes can be used to promote, monitor, assess and provide feedback on the development of students' graduate attributes even in subjects like Structural Design 1 where specific discipline content is taught.

In Structural Design 1 a group project is combined with self and peer assessment processes to develop students' skills to design various reinforced concrete elements. The process requires students to not only apply their engineering knowledge and use judgement in making design decisions, but to articulate and explain their design. The process of critically evaluating their own and their team members' work and behaviour is explicitly linked to the assessment tasks by using criteria that address the subject learning outcomes. The feedback sessions play a significant role in engaging students with developing both their technical and more generic professional skills.

Ongoing research is focussed on providing more efficient and effective resources for these feedback sessions.

\section{References}

[1] LANG J. D., CRUSE S., MCVEY F. D., and MCMASTERS J., "Industry expectations of new engineers: A survey to assist curriculum designers," Journal of Engineering Education, vol. 88, pp. 43, 1999.

[2] SCOTT G. and YATES K. W., "Using successful graduates to improve the quality of undergraduate engineering programmes," European Journal of Engineering Education, vol. 27, pp. 363, 2002.

[3] MEIER R. L., WILLIAMS M. R., and HUMPHREYS M. A., "Refocusing our efforts: Assessing non-technical competency gaps," Journal of Engineering Education, vol. 89, pp. 377,2000 .

[4] BRYAN R. M. M., CASE J., FRASER D., "Engineering graduates' perceptions of how well they were prepared for work in industry," European Journal of Engineering Education, vol. 30, pp. 167 - 180, 2005.

[5] BOUD, D., and FALCHIKOV, N. Rethinking Assessment in Higher Education Learning for the Longer Term. Routledge, 2007

[6] PONT B., and WERQUIN P., Competencies for the knowledge economy, Education Policy Analysis, Chapter 4 OECD, Paris 2001.

[7] DEST (2002), Employability skills for the future: project final report, http://www.dest.gov.au/archive/ty/publications/employability_skills/final_report.pdf last viewed July 2007.

[8] ABET (2007), Leadership and quality assurance in applied science, computing, engineering, and communication. http://www.abet.org/ last viewed July, 2007

[9] TREVELYAN J., (2007) “Technical Coordination in Engineering Practice”, Journal of Engineering Education 96(3). pp. 191 - 204.

[10] TREVELYAN J., (2007) “The 'Random Madness' of Work”, ASEE Prism 17(1). pp. 51. 
[11] NATISHAN, M. E., SCHMIDT L. C., et al. (2000). "Student focus group results on student team performance issues." Journal of Engineering Education 89(3): 269.

[12] MESSER, D. (2001). 'Teamwork : the heart of engineering projects.' 12th Australasian Conference of Engineering Education, Queensland University of Technology.

[13] STONYER H., DODD D., et al. (2001). "Enhancing group work in engineering". 12th Australasian Conference of Engineering Education, Queensland University of Technology.

[14] BOUD D., and FALCHIKOV N. (2006) “Aligning Assessment with long-term learning", Assessment and Evaluation in Higher Education, 31, 4: pp. 399 -- 413.

[15] GOLDFINCH, J., (1994). "Further developments in peer assessment of group projects", Assessment \& Evaluation in Higher Education Vol. 19, pp. 29: Carfax Publishing Company.

[16] GOLDFINCH, J., and RAESIDE, R., (1990). "Development of a Peer Assessment Technique for Obtaining Individual Marks on a Group Project". Assessment and Evaluation in Higher Education, 15(3), 210- 231.

[17] FALCHIKOV, N., and GOLDFINCH, J., (2000). "Student Peer Assessment in Higher Education: A Meta-Analysis Comparing Peer and Teacher Marks". Review of Educational Research, 70(3), 287-322.

[18] WILLEY K, and FREEMAN M. (2006), "Improving teamwork and engagement: the case for self and peer assessment", Australasian Journal of Engineering Education. Online publication 2006-02 http://www.aaee.com.au/journal/2006/willey0106.pdf

[19] WILLEY K, and FREEMAN M., (2006), "Completing the learning cycle: The role of formative feedback when using self and peer assessment to improve teamwork and engagement". Proceedings of the 17th Annual Conference of the Australasian Association for Engineering Education, 10 -13th December 2006, Auckland, New Zealand.

[20] ENGINEERS AUSTRALIA (2004), Australia Engineering Competency Standards - Stage 1 Competency Standards for Professional Engineers, downloaded from http://www.engineersaustralia.org.au/ on 30 June 2007.

[21] FREEMAN M. and MCKENZIE J. (2002), "SPARK, A Confidential Web-Based Template for Self and Peer Assessment of Student Teamwork: Benefits of Evaluating across Different Subjects”, British Journal of Educational Technology, vol. 33, pp. 551-569.

[22] SPARK, Self and Peer Assessment Resource Kit, http://www.educ.dab.uts.edu.au/darrall/sparksite/ last viewed Sept 2007.

[23] WILLEY K, JACOBS B., and WALMSLEY M., (2007) "Self and Peer Assessment to Promote Professional Skill Development: Moving from Ad-hoc to Planned Integration" Proceedings of the 18th Annual Conference of the Australasian Association for Engineering Education, 9 -13th December, Melbourne,Australia.

[24] STANDARDS AUSTRALIA (2002), AS/NZ1170: Structural Design Actions, Australia, Australian Standards.

[25] STANDARDS AUSTRALIA (2001), AS3600: Concrete Structures, Australia, Australian Standards. 